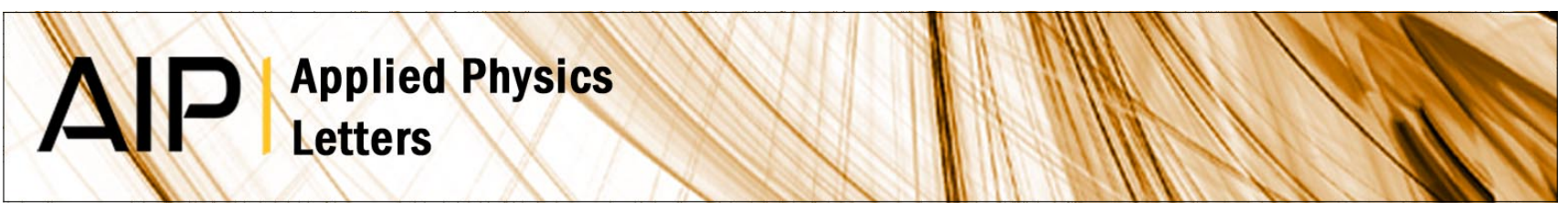

\title{
Enhanced nonlinear optical properties of oxygen deficient lead-niobium- germanate film glasses
}

J. Gonzalo, H. Fernandez, J. Solis, D. Munoz-Martin, J. M. Fernandez-Navarro et al.

Citation: Appl. Phys. Lett. 90, 251907 (2007); doi: 10.1063/1.2749837

View online: http://dx.doi.org/10.1063/1.2749837

View Table of Contents: http://apl.aip.org/resource/1/APPLAB/v90/i25

Published by the American Institute of Physics.

\section{Related Articles}

Experimental generation of a radially polarized beam with controllable spatial coherence Appl. Phys. Lett. 100, 051108 (2012)

Complete energy transfer due to rare-earth phase segregation in optical fiber preform glasses

J. Appl. Phys. 110, 083121 (2011)

Fabrication of glass micro-cavities for cavity quantum electrodynamics experiments

Appl. Phys. Lett. 99, 171112 (2011)

Observation of the Plateau-Rayleigh capillary instability in multi-material optical fibers

Appl. Phys. Lett. 99, 161909 (2011)

Attenuated total reflection $\mathrm{GeO} 2$ hollow waveguide for $9.6-11.7 \mu \mathrm{m}$ infrared light transmission Appl. Phys. Lett. 99, 161107 (2011)

\section{Additional information on Appl. Phys. Lett.}

Journal Homepage: http://apl.aip.org/

Journal Information: http://apl.aip.org/about/about_the_journal

Top downloads: http://apl.aip.org/features/most_downloaded

Information for Authors: http://apl.aip.org/authors

\section{ADVERTISEMENT}

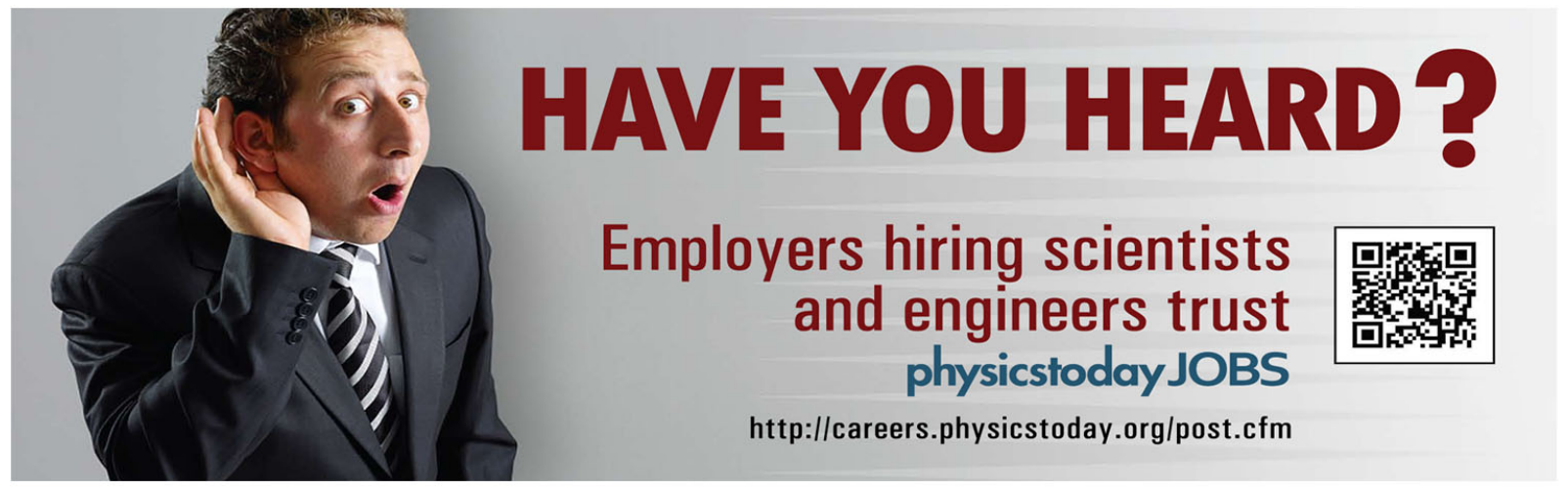




\title{
Enhanced nonlinear optical properties of oxygen deficient lead-niobium-germanate film glasses
}

\author{
J. Gonzalo, ${ }^{\text {a) }}$ H. Fernandez, J. Solis, D. Munoz-Martin, \\ J. M. Fernandez-Navarro, and C. N. Afonso \\ Laser Processing Group, Instituto de Optica, CSIC, Serrano 121, 28006 Madrid, Spain \\ J. L. G. Fierro \\ Instituto de Catálisis y Petroleoquímica, CSIC, Marie Curie s/n, 28049 Cantoblanco, Spain
}

(Received 19 April 2007; accepted 24 May 2007; published online 19 June 2007)

\begin{abstract}
The third order nonlinear optical properties of oxygen deficient lead-niobium-germanate film glasses with heavy metal contents beyond that of the bulk glass formation region have been investigated. Values of the nonlinear third order optical susceptibility up to $/ \chi^{(3)} / \approx 1.8$ $\times 10^{-11}$ esu have been measured by degenerate four wave mixing at $800 \mathrm{~nm}$ in films having large heavy metal fractions $(0.93)$. The fast buildup and decay times $(\approx 130 \mathrm{fs})$ of the nonlinear response confirm its nonresonant character. The partial reduction of $\mathrm{Nb}^{5+}$ to $\mathrm{Nb}^{4+}$ evidenced by $\mathrm{x}$-ray photoelectron spectroscopy, which is associated with the oxygen deficiency, appears to be responsible for the strong enhancement of $/ \chi^{(3)} /$. () 2007 American Institute of Physics.
\end{abstract}

[DOI: $10.1063 / 1.2749837$ ]

All-optical communication technologies require materials suitable for the design and fabrication of integrated photonic devices. ${ }^{1}$ Heavy metal oxide (HMO) glasses having large $\mathrm{Pb}$ or $\mathrm{Bi}$ fractions exhibit properties that make them attractive for these applications. They are chemically stable, show a broad transparence range $(0.4<\lambda<8 \mu \mathrm{m}),{ }^{2}$ have low phonon energies $\left(\sim 800 \mathrm{~cm}^{-1}\right)$, present high linear refractive indices $\left(n_{0} \geqslant 2\right)$, and have large third order nonlinear optical susceptibilities $\left(\chi^{(3)}\right)$ with respect to fused silica. ${ }^{2-5}$

The nonlinear optical properties of bulk HMO glasses have been extensively studied during the last years. ${ }^{5-11} \mathrm{Ex}-$ perimental results demonstrate that the strength of the nonlinear response relates to the concentration of highly polarizable cations, such as empty $d$-band transition metals $\left(\mathrm{Nb}^{5+}, \mathrm{Ti}^{4+}\right)$ or heavy metals having lone $s^{2}$ electron pairs $\left(\mathrm{Pb}^{2+}, \mathrm{Bi}^{3+}\right) .{ }^{3,9}$ However, the glass formation region tends to be reduced in some cases such as $\mathrm{Nb}$ containing glasses, thus limiting the glass design possibilities. In a previous work, we showed that lead-niobium-germanate film glasses with large heavy metal fractions could be produced by pulsed laser deposition (PLD). ${ }^{11,12}$ Film glasses were oxygen deficient, and yet they were transparent with a $n_{0}$ and an optical energy gap $E_{g}$ that depended on the heavy metal content. In this letter we report the nonlinear optical response of these film glasses in the femtosecond regime, compare it to that of transparent bulk glasses and discuss the origin of the strong enhancement observed.

Table I summarizes the composition and linear optical properties of the bulk glasses and the films produced from them by PLD taken from a previous work. ${ }^{12}$ The compositional changes observed in the films with respect to the bulk glasses, namely, a slight increase of the heavy metal fraction and a significant oxygen deficiency, were found to have a clear effect on the optical properties of the films. Only bulk glasses having $[\mathrm{Pb}]+[\mathrm{Nb}] \leqslant 0.6$ were transparent, while all film glasses were transparent and with a value of the imagi-

${ }^{a)}$ Electronic mail: j.gonzalo@io.cfmac.csic.es nary part of the refractive index, $k<10^{-4}$. The most significant difference between film and bulk glasses is the significant increase of $E_{g}$ in the films with respect to bulk glasses. This is illustrated in Fig. 1 where the absorbance spectra measured for the G10B bulk glass and for two films deposited on sapphire having the smallest and the largest $[\mathrm{Pb}]$ $+[\mathrm{Nb}]$ fractions are shown. The blueshift of the cutoff wavelength observed when comparing the film $(\mathrm{G} 10 \mathrm{~F})$ to the corresponding bulk glass (G10B) is most likely a consequence of the oxygen deficiency of the films that leads to an increase of the fraction of bridging oxygen bonds. The oscillations observed in the film spectra are related to interference effects at the air/glass and the glass/substrate interfaces, whereas the high level of the base line is related to scattering and high surface reflection caused by the high $n_{0}$ of the films.

The third order nonlinear optical properties have been analyzed at $\lambda=800 \mathrm{~nm}$ by degenerate four wave mixing using the forward folded box configuration ${ }^{11,13}$ and a $1 \mathrm{kHz}$ repetition rate femtosecond Ti:sapphire regenerative amplifier laser system as excitation source. The pulse compressor of the amplifier was adjusted to precompensate the dispersion of the optical elements located in front of the sample in order to produce the shortest possible pulse at the sample ( $\sim 100 \mathrm{fs})$. The beam has been split in three parallel arms with equal power, allowing separate control of the delay and polarization. They are overlapped at the sample by means of a $75 \mathrm{~mm}$ focal length lens leading to a waist of $\approx 40 \mu \mathrm{m}$. We have used copolarized pulses, and thus the evolution of the conjugated signal is a measure of the modulus of the diagonal component of the $\chi^{(3)}$ tensor $\left(/ \chi_{x x x x}^{(3)} /\right)$ that will be referred to from now on as $/ \chi^{(3)} /$. The intensity of the conjugated beam follows the characteristic cubic dependence with the pump beam intensity. $/ \chi^{(3)} /$ has finally been evaluated by using fused silica as reference material $\left(/ \chi^{(3)} / \mathrm{SiO}_{2}=1.5 \pm 0.5\right.$ $\left.\times 10^{-14} \mathrm{esu}\right) .{ }^{13}$ In the case of film glasses, the contribution of the substrate to the measured conjugated signal was carefully subtracted. 
TABLE I. Composition (in \% molar) of $X \mathrm{PbO}-\mathrm{YNb}_{2} \mathrm{O}_{5}-\mathrm{ZGeO}_{2}$ bulk glasses, heavy metal fraction ([Pb] $+[\mathrm{Nb}])$, oxygen content $([\mathrm{O}])$, linear refractive index $\left(n_{0}\right.$, at $\left.\lambda=800 \mathrm{~nm}\right)$, optical gap $E_{g}$ (in eV), and binding energies of $\mathrm{Nb} 3 d_{5 / 2}$ core electron level for $\mathrm{Nb}^{+5}$ and $\mathrm{Nb}^{+4}$ (in eV) determined within $\pm 0.1 \mathrm{eV}$ and measured for the studied bulk (GXXB) and film (GXXF) glasses. The values in brackets for $\mathrm{Nb} 3 d_{5 / 2}$ levels correspond to the $\%$ of $\mathrm{Nb}$ ions. Compositional and optical data were taken from Ref. 12.

\begin{tabular}{cccccccc}
\hline \hline Glass & $X-Y-Z$ & $([\mathrm{~Pb}]+[\mathrm{Nb}])$ & {$[\mathrm{O}]$} & $n_{0}$ & $E_{g}$ & $\mathrm{Nb}^{+5} 3 d_{5 / 2}$ & $\mathrm{Nb}^{+4} 3 d_{5 / 2}$ \\
\hline G10B & $25-15-60$ & 0.48 & 1.91 & 1.97 & 2.97 & $206.9(100)$ & $\ldots$ \\
G1B & $25-25-50$ & 0.60 & 2.00 & 2.05 & 2.75 & $206.9(100)$ & $\ldots$ \\
G7B $^{\mathrm{a}}$ & $35-35-30$ & 0.78 & 2.00 & $\cdots$ & $\cdots$ & $\cdots$ & $\ldots$ \\
G40B $^{\mathrm{a}}$ & $35-55-10$ & 0.94 & 2.13 & $\cdots$ & $\cdots$ & $\ldots$ & $\ldots$ \\
G10F & G10B $^{\mathrm{b}}$ & 0.53 & 1.68 & 2.02 & 3.62 & $207.2(45)$ & $205.7(55)$ \\
G1F & G1B $^{\mathrm{b}}$ & 0.62 & 1.80 & 2.07 & 3.52 & $207.0(30)$ & $206.1(70)$ \\
G7F & G7B $^{\mathrm{b}}$ & 0.83 & 1.72 & 2.14 & 3.45 & $206.9(32)$ & $206.0(68)$ \\
G40F & G40B $^{\mathrm{b}}$ & 0.93 & 1.72 & 2.24 & 3.40 & 206.8 & 206.0 \\
\hline \hline
\end{tabular}

${ }^{\mathrm{a} N o n t r a n s p a r e n t ~(o p a l) ~ g l a s s . ~}$

${ }^{\mathrm{b}}$ In the case of film glasses, the corresponding bulk target is indicated.

Figure 2 shows that the $/ \chi^{(3)} /$ glass $/ / \chi^{(3)} / \mathrm{SiO} 2$ ratio increases as $[\mathrm{Pb}]+[\mathrm{Nb}]$ increases both for films and bulk glasses. The $/ \chi^{(3)} /$ values of film glasses $\left(\sim 10^{-12}-10^{-11} \mathrm{esu}\right)$ are at least one order of magnitude higher than those of transparent bulk glasses having a similar heavy metal fraction $\left(\sim 10^{-13}\right.$ esu), and up to three orders of magnitude higher than that of fused silica. The dependence of $/ \chi^{(3)} /$ with $[\mathrm{Pb}]+[\mathrm{Nb}]$ is in good agreement both with semiempirical models for nonresonant optical nonlinearities s-5,7,8 $^{3-1}$ and earlier results reported for glasses having large $\mathrm{Pb}$ or $\mathrm{Nb}$ fractions. ${ }^{5-11}$ The structural changes induced by large $\mathrm{Pb}$ or $\mathrm{Nb}$ fractions, such as $\mathrm{Pb}$ acting as network former with tetrahedral $\left[\mathrm{PbO}_{4}\right]$ or octahedral configuration $\left[\mathrm{PbO}_{6}\right]$ and $\mathrm{Nb}$ forming chains or even three-dimensional associations of $\left[\mathrm{NbO}_{6}\right]$ octahedral groups through the formation of $\mathrm{Nb}-\mathrm{O}-\mathrm{Nb}$ bonds, ${ }^{6,9}$ were reported to increase the hyperpolarizability of both cations, ${ }^{7,10,14}$ and consequently led to an enhancement of $\chi^{(3)}$.

However, the fact that $/ \chi^{(3)} /$ in film glasses is much higher than in the corresponding bulk glasses suggests additional factors contributing to $/ \chi^{(3)} /$ in the films. The optical energy gap is $E_{g} \geqslant 3.4 \mathrm{eV}$ for film glasses, while the photon energy at $800 \mathrm{~nm}$ is $E_{\mathrm{ph}}=1.55 \mathrm{eV}$. Thus the limit condition for two photon absorption (TPA) to occur, given by $2 E_{\mathrm{ph}}$ $\geqslant E_{g}{ }^{3}$ is not satisfied. An additional contribution to resonant nonlinearity would be the presence of TPA at defect bands in the UV-visible. In particular, the existence of a charge trans-

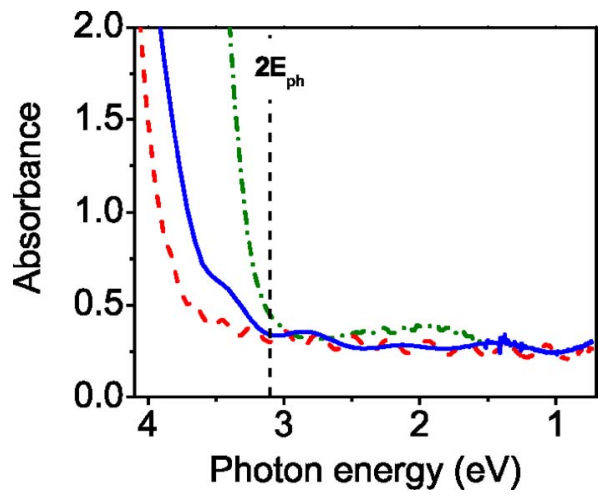

FIG. 1. (Color online) Absorbance measured for a (dash-dotted) G10B bulk glass and for the films having the (dashed) smallest and the (solid) largest $[\mathrm{Pb}]+[\mathrm{Nb}]$ fractions $(\mathrm{G} 10 \mathrm{~F}$ and $\mathrm{G} 40 \mathrm{~F}$, respectively). The vertical line corresponds to twice the photon energy at $800 \mathrm{~nm}\left(2 E_{\mathrm{ph}}=3.11 \mathrm{eV}\right)$. fer band related to electronic transfer $\left(\mathrm{O}^{2-}+\mathrm{Nb}^{5+} \rightarrow \mathrm{O}^{-}\right.$ $+\mathrm{Nb}^{4+}$ ) has been reported for $\mathrm{Nb}$ containing glasses. ${ }^{15}$ This band is not always observed ${ }^{6,10}$ and when observed, it is in the near UV $(3.3-3.6 \mathrm{eV})$ and thus, it should not lead to significant TPA in the present case. In addition, the extremely fast $(<1 \mathrm{ps})$ buildup time of the nonlinear response observed in our case, as illustrated in the inset of Fig. 2, allows us to discard nonlinear absorptive contributions to $\chi^{(3)}$ as the origin of the enhanced nonlinear response of film glasses. At the wavelengths of interest for optical communications, such as $1.55 \mu \mathrm{m}, / \chi^{(3)} /$ in the films is expected to be similar to those presented in Fig. 2, since the probability of two photon absorption is negligible at that wavelength $\left[2 E_{\mathrm{ph}}(1.55 \mu \mathrm{m})\right.$ $\left.=1.66 \mathrm{eV} \ll E_{g}\right]$.

The origin of the strong enhancement of $/ \chi^{(3)} /$ must instead be related to the oxygen deficiency observed in film glasses $(\approx 10 \%-15 \%$, Table I), since it must increase the fraction of bridging oxygen bonds to maintain the glass structure, and this has to occur along with the partial reduction of the cations present in the glass. The oxidation state of cations and the composition of glasses have been determined by x-ray photoelectron spectroscopy (XPS) using a $\mathrm{Mg} K \alpha$ $\mathrm{x}$-ray source $(1253.6 \mathrm{eV})$. The background pressure during the analysis was below $2 \times 10^{-9}$ mbar. The binding energy scale was calibrated versus the Au $4 f_{7 / 2}$ level (Au metal) at $83.8 \mathrm{eV}$ and depth profiling was achieved by $\mathrm{Ar}^{+}$sputtering $\left(1.7 \mathrm{kV}\right.$, sputtering rate of $\left.\sim 1 \mathrm{~nm} \mathrm{~min}{ }^{-1}\right)$. The composition

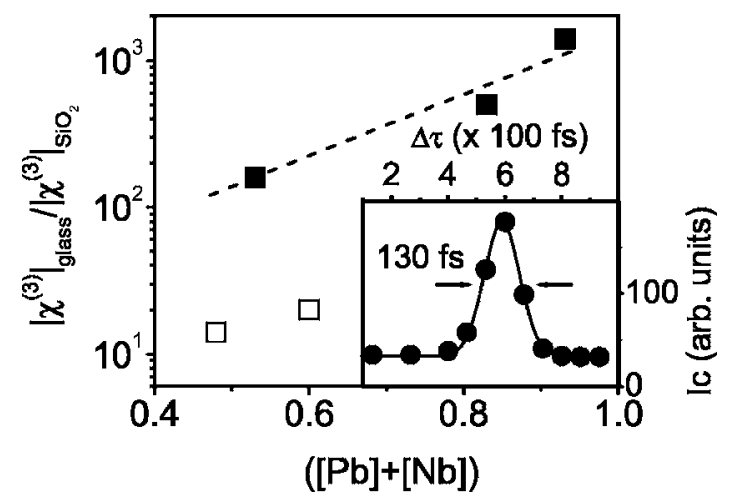

FIG. 2. Dependence of $(\square, \square)$ the $/ \chi^{(3)} /$ glass $/ / \chi^{(3)} / \mathrm{SiO} 2$ ratio with the heavy metal $([\mathrm{Pb}]+[\mathrm{Nb}])$ content for $(\mathbb{\square})$ film and $(\square)$ transparent bulk glasses. The dashed line is a guide for the eyes. The inset shows the time evolution of the nonlinear response for a $25 \mathrm{PbO}-15 \mathrm{Nb}_{2} \mathrm{O}_{5}-60 \mathrm{GeO}_{2}$ bulk glass. 


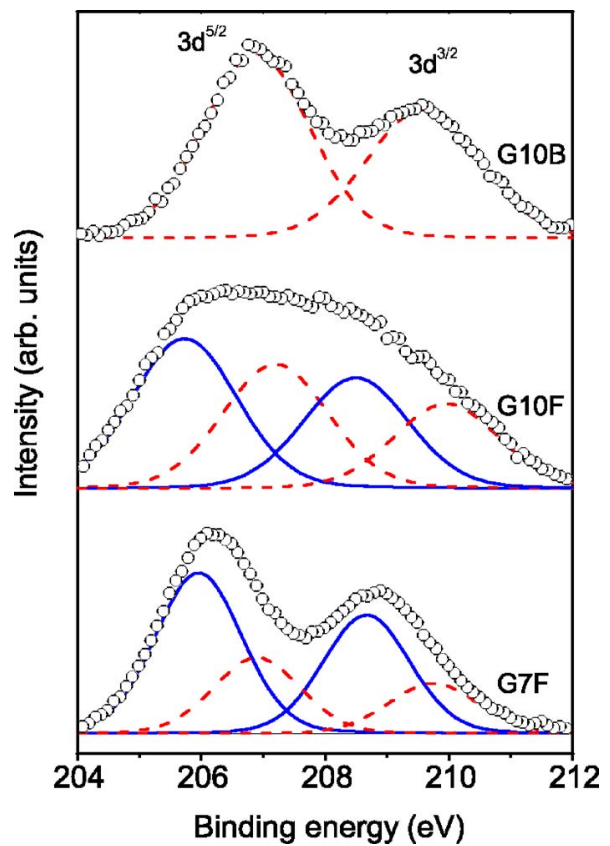

FIG. 3. (Color online) Nb $3 d$ core-level spectra of G10B (bulk), G10F, and $\mathrm{G} 7 \mathrm{~F}$, (films) glasses. The dashed and solid lines correspond to $\mathrm{Nb}^{5+}$ and $\mathrm{Nb}^{4+}$ bands, respectively.

determined by XPS was in all cases within $5 \%$ the one reported earlier ${ }^{12}$ and shown in Table I.

The $\mathrm{Nb} 3 d$ core-level spectrum is shown in Fig. 3 for the G10B bulk glass. The peaks at 206.9 and $209.6 \mathrm{eV}$ correspond to the $\mathrm{Nb}^{5+} 3 d_{5 / 2}$ and $3 d_{3 / 2}$ levels, respectively. The spectra obtained for films glasses show broader peaks, as illustrated by the spectra of G10F and G7F film glasses. The spectrum of G10F shows only a broad peak, that is compatible with the presence of additional bands associated with the presence of $\mathrm{Nb}^{4+}$ peaking at $205.7\left(3 d_{5 / 2}\right)$ and $208.5 \mathrm{eV}$ $\left(3 d_{3 / 2}\right){ }^{16}$ The spectrum for G7F films presents two peaks, that are broader and shifted to lower energies than in the case of the G10B bulk glass indicating that the $\mathrm{Nb}^{4+}$ bands are the most intense. The measured binding energies of $\mathrm{Nb} 3 d_{5 / 2}$ levels for bulk and film glasses are shown in Table I. $\mathrm{Nb}^{4+}$ bands are observed in all films, the only difference being the relative intensity of the $\mathrm{Nb}^{5+}$ and $\mathrm{Nb}^{4+}$ contributions. The fraction of $\mathrm{Nb}^{4+}$ is above $50 \%$ in all cases, and it increases with the heavy metal fraction. A possible reduction of $\mathrm{Pb}$ or Ge has been discarded by analyzing the most intense $\mathrm{Pb} 4 f_{7 / 2}$ and $\mathrm{Ge} 2 p_{3 / 2}$ levels. Only $\mathrm{Pb}^{2+}$ and $\mathrm{Ge}^{+4}$ were found both in bulk or film glasses, with binding energies of $137.5 \pm 0.2$ and $1219.3 \pm 0.1 \mathrm{eV}$, respectively. $\mathrm{Nb}^{+4}$ presents the same octahedral coordination than $\mathrm{Nb}^{5+}$. This similar coordination together with the necessary increase of the fraction of bridging bonds should favor the formation of $\mathrm{Nb}-\mathrm{O}-\mathrm{Nb}$ bonds. ${ }^{6,9}$ From the optical point of view, the presence of a single elec- tron in the $4 d$ shell would enhance the polarizability of the ion, ${ }^{14}$ and this should contribute to the increase of $/ \chi^{(3)} /$. It must be noted here though that $\mathrm{Nb}^{+4}$ should lead to a reduced transmission in the visible range. ${ }^{3,16}$ However, this is not the case, as shown in Fig. 1.

In summary, oxygen deficient transparent $\mathrm{PbO}-\mathrm{Nb}_{2} \mathrm{O}_{5}-\mathrm{GeO}_{2}$ film glasses with heavy metal contents beyond that of the bulk glass formation region show values of the third order optical susceptibility as high as $/ \chi^{(3)} /$ $\approx 1.8 \times 10^{-11} \mathrm{esu}$, that is $10^{3}$ times higher than that of fused silica. The fast buildup and decay times of the nonlinear response supports the nonresonant character of the nonlinear response. The presence of $\mathrm{Nb}^{4+}$ combined with the formation of $\mathrm{Nb}-\mathrm{O}-\mathrm{Nb}$ bonds with a large hyperpolarizability is proposed as mechanisms responsible for the enhancement of $/ \chi^{(3)} /$. The fast nonlinear response times $(\tau<1 \mathrm{ps})$ and large figure of merit ${ }^{4,5}\left(/ \chi^{(3)} / \tau^{-1} \alpha^{-1}>3 \times 10^{-2} \mathrm{~cm}^{3} / \mathrm{W} \mathrm{s}\right)$ of $\mathrm{PbO}-\mathrm{Nb}_{2} \mathrm{O}_{5}-\mathrm{GeO}_{2}$ film glasses make them candidates for optical beam processing applications.

This work has been partially funded by the Spanish Ministry of Education and Science (Project Nos. MAT200506508-C02-01 and TEC2005-00074/MIC). Two of the auhtors (H.F. and D.M.-M.) respectively acknowledge grants from the Spanish Ministry of Education and Science and the CSIC-European Social Fund I3P Program.

${ }^{1}$ G. I. Stegeman and R. H. Stolen, J. Opt. Soc. Am. B 6, 652 (1989).

${ }^{2}$ W. H. Dumbaugh and J. C. Lapp, J. Am. Ceram. Soc. 75, 2315 (1992).

${ }^{3}$ M. E. Lines, J. Appl. Phys. 69, 6876 (1991).

${ }^{4}$ E. M. Vogel, M. J. Weber, and D. M. Krol, Phys. Chem. Glasses 32, 231 (1991).

${ }^{5}$ A. Jha, X. Liu, A. K. Kar, and H. T. Bookey, Curr. Opin. Solid State Mater. Sci. 5, 475 (2001).

${ }^{6}$ T. Cardinal, E. Fargin, G. Le Flem, and S. Leboiteux, J. Non-Cryst. Solids 222, 228 (1997).

${ }^{7}$ K. Terashima, T. H. Shimoto, and T. Yoko, Phys. Chem. Glasses 38, 211 (1997).

${ }^{8}$ G. Vijaya Prakash, D. Narayana Rao, and A. K. Bhatnagar, Solid State Commun. 119, 39 (2001).

${ }^{9}$ S. Santran, L. Canioni, L. Sarger, T. Cardinal, and E. Fargin, J. Opt. Soc. Am. B 21, 2180 (2004).

${ }^{10}$ J. Lin, W. Huang, Z. Sun, Ch. S. Ray, and D. E. Day, J. Non-Cryst. Solids 336, 189 (2004).

${ }^{11}$ V. Diez, H. Fernandez, O. Sanz, C. N. Afonso, J. M. Fernandez-Navarro, J. Gonzalo, M. Jimenez de Castro, A. Perea, J. Siegel, and J. Solis, Proceedings of the 4th Meeting of the Spanish Society of Optoelectronics, 2005, p. 257.

${ }^{12}$ J. Gonzalo, O. Sanz, J. M. Fernández Navarro, C. N. Afonso, and J. García López, Appl. Phys. A: Mater. Sci. Process. 76, 743 (2003).

${ }^{13}$ R. L. Sutherland, Handbook of Nonlinear Optics (Dekker, New York, 1996), p. 527.

${ }^{14}$ E. M. Vogel, S. G. Kosinski, D. M. Krol, J. L. Jackel, S. R. Friberg, M. K. Oliver, and J. D. Powers, J. Non-Cryst. Solids 107, 244 (1989).

${ }^{15}$ F. F. Sene, J. R. Martinelli, and L. Gomes, J. Non-Cryst. Solids 348, 63 (2004).

${ }^{16}$ N. Özer, M. D. Rubin, and C. M. Lampert, Sol. Energy Mater. Sol. Cells 40, 285 (1996). 